\title{
IDENTIDADE E ESTRATÉGIA NA FORMAÇÃO DO MOVIMENTO AMBIENTALISTA BRASILEIRO'
}

\author{
Angela Alonso, \\ VALERIANO COSTA E \\ DÉBORA MACIEL
}

\section{RESUMO}

A partir de uma síntese conceitual entre as teorias do Processo Político e dos Novos Movimentos Sociais, o artigo analisa as dimensões estratégicas e simbólicas do processo de formação do movimento ambientalista brasileiro. Argumenta-se que três estruturas de oportunidades políticas - o processo de Redemocratização, a Assembléia Constituinte e a Rio-92 - deram os parâmetros para que grupos de ativistas ambientalistas se constituíssem e enfrentassem dilemas comuns relativos a seus frames e estratégias de mobilização, constituindo, ao longo desse processo, uma identidade compartilhada.

\begin{abstract}
PALAVRAS-CHAVE: movimento ambientalista; estrutura de oportunidade política; identidade coletiva; estratégias de mobilização.
\end{abstract}

\section{SUMMARY}

Relying on a conceptual synthesis provided by the Political Process and New Social Movement theories, this article analyses the strategic and symbolic dimensions of the Brazilian environmental movement's formation process. The authors argue that three political opportunity structures - Redemocratization, Constituent Assembly and Rio 92 - provided the parameters for environmental groups to arise and face common dilemmas regarding their frames and mobilizing strategies. Through this process, a shared identity came about.

KEYWORDS: Brazilian environmental movement; political opportunity structure; collective identity; mobilizing strategy.

\footnotetext{
[1] Este artigo é uma versão resumida de "The formation of the Brazilian environmental movement", publicada no IDS Working Paper, n. 259 , em novembro de 2005 , e resulta do projeto Trajetórias dos Ativistas Ambientalistas Brasileiros, desenvolvida no Cebrap entre abril de 2003 e dezembro de 2004, no âmbito do Development Research Centre on Citizenship da Universidade de Sussex, que junto com The William and Flora Hewlett Foundation financiou a pesquisa. Agradecemos os comen-
}

Em julho de 1982, às margens das cataratas de Foz do Iguaçu, em Guaíra, 3 mil pessoas participaram de um quarup em protesto contra a construção da hidrelétrica de Itaipu, que ameaçava o Parque Nacional de Sete Quedas: “Ao som melancólico e compassado de um tambor, levando uma muda de árvore e uma bandeira branca com uma pétala ao centro, em forma de lágrima, além da faixa 'Sete Quedas Viverá', os manifestantes fizeram sete paradas durante o percurso" 2 . Organizado por uma coalizão de pequenos grupos ambientalistas de diversas regiões do país, o Quarup Adeus Sete-Quedas incluiu atos políticos e culturais ao longo de três dias. 
Itaipu era uma das obras magnas do plano desenvolvimentista levado a cabo pelos governos militares. Ao contestá-la, os ativistas ambientalistas contestavam, em decorrência, o próprio regime autoritário. O episódio revela, pois, a conexão do movimento ambientalista em suas origens com o movimento pela Redemocratização. Embora essa característica seja saliente em vários eventos contemporâneos ao Adeus Sete Quedas, a vasta literatura sobre movimentos sociais que se constituiu no Brasil durante o ciclo de protestos da Redemocratização, inspirada no marxismo, privilegiou os movimentos populares e deu pouca atenção ao ativismo ambientalista, mais restrito à classe média. O processo de formação e a dinâmica interna do movimento ambientalista brasileiro motivaram poucas análises sistemáticas, restringindo-se, na maior parte, a estudos de caso33.

Assim como as mobilizações coletivas estimularam a proliferação dos estudos, o arrefecimento delas, concluída a Redemocratização, esvaziou essa agenda de pesquisa. Na verdade, a institucionalização de vários movimentos sociais, sob forma de associações formais ou de partidos políticos, foi interpretada negativamente por boa parte da literatura, como sinal de desmobilização ou cooptação. Esse juízo foi contrastado, na virada dos anos 1980 para os 1990, por estudos que demonstraram que o aparente declínio dos movimentos sociais podia ser explicado pela dinâmica de sua interação com o Estado e pelos dilemas daí decorrentes acerca de estratégias, ou então pelo próprio caráter fluido dos movimentos, com os picos e baixas de mobilização, típico dos ciclos de protesto 4 .

Contudo, nos anos 1990, a literatura não seguiu essas pistas. Com a crise do marxismo e a incorporação da Teoria dos Novos Movimentos Sociais, as análises se deslocaram dos movimentos sociais populares para movimentos "pós-materiais", vistos como os novos agentes coletivos da mudança social e política. Ganhou relevo a dimensão culturale simbólica das mobilizações, sobretudo a formação de identidades coletivas ${ }^{5}$. Foi então que a questão ambiental vingou como objeto de estudos no Brasil - conjugada a temas como mulheres, negros e homossexuais. Entretanto, simultaneamente, sob a égide de reformulações dos conceitos de "sociedade civil" e de "esfera pública", os próprios estudos sobre movimentos sociais perderam fôlego, sendo substituídos por análises sobre o associativismo e a participação da sociedade civil em fóruns deliberativos e na prestação de serviços ao Estado ${ }^{6}$. As análises sobre a questão ambiental seguiram esse rumo ${ }^{7}$, deixando de lado o problema da constituição de um movimento social ambientalista.

É justamente essa questão que motiva este artigo. Procuramos reconstituir o processo de formação do movimento ambientalista brasileiro seguindo a tendência de combinação das duas principais tradições de explicação na área, a Teoria dos Novos Movimentos Sociais e a tários de Ian Scoones, Lisa Thompson e Peter Houtzager e o auxílio de nossa assistente de pesquisa, Adriana dos Santos.

[2] O Estadode S. Paulo, 25/7/1982.

[3] Caso, respectivamente, de Viola, Eduardo. "Movimento ecológico e heterogeneidade política". Lua Nova, v. 3, n. 4, São Paulo, Cedec, abr.-jun. 1987, e de Antuniassi, Maria Helena. Movimento ambientalista em São Paulo: análise sociológica de um movimento social urbano. São Paulo: Ceru, 1989.

\footnotetext{
[4] Argumentos presentes, respectivamente, em Cardoso, Ruth. "A trajetória dos movimentos sociais". In: Dagnino, Evelina (org.). Anos 9o: política e sociedade no Brasil. São Paulo: Brasiliense, 1994; Boschi, Renato Raul. A arte da associação. Política de base e democracia no Brasil. Rio de Janeiro: Iuperj, 1987, e Ottmann, Götz. "Movimentos sociais urbanos e democracia no Brasil. Uma abordagem cognitiva". Novos Estudos Cebrap, n. 41, mar 1995.
}

[5] Alvarez, Sônia, Dagnino, Evelina e Escobar,Arturo (orgs.).Cultura e política nos movimentos sociais latinoamericanos. Novas leituras. Belo Horizonte: Editora UFMG, 2000.

[6] Por exemplo, Dagnino, Evelina (org.). Sociedade civil e espaços públicos no Brasil. São Paulo: Paz e Terra, 1994.

[7] Alonso, Angela e Costa, Valeriano. "Ciências sociais e meio ambiente no Brasil: um balanço bibliográfico". BIB - Revista Brasileira de Informações Bibliográficas em Ciências Sociais, Anpocs, n. 53, 2002, pp. 35-78. 
[8] Síntese formulada, por exemplo, por Diani, Mario. Green networks. A structural analysis of the Italian environmental movement. Edimburgo: Edinburgh University Press, 1995.

[9] A pesquisa consistiu em entrevistas diretivas com lideranças, coleta de informações na imprensa diária e nos arquivos e sites de onze associações que tomaram parte em campanhas e eventos de protesto ambiental no Brasil dos anos 1970 ao início dos 1990: FBCN (Fundação Brasileira para a Conservação da Natureza), Agapan (Associação Gaúcha de Proteção ao Ambiente Natural), Mape (Movimento Arte e Pensamento Ecológico), APPN (Associação Paulista para Proteção Natural), Oikos -Amigos da Terra, PV (Partido Verde), Funatura (Fundação para Natureza), SOS Mata Atlântica, GreenpeaceBrasil, WWF-Brasil e ISA (Instituto Socioambiental).

[10] Tarrow, Sidney. Power in movement - Social movements, collective action and politics. Nova York: Cambridge University Press, 1998, p. 20.

[11] Kriesi, Hanspeter. New social movements in Western Europe.A comparative analysis. Minneapolis: The University of Minnesota Press, 1995.
Teoria do Processo Político, patente na literatura internacional dos anos $1990^{8}$. Em consonância, atentaremos aqui tanto para as dimensões materiais e estratégicas, ressaltadas pela Teoria do Processo Político - isto é, as estruturas de oportunidades políticas nas quais grupos ambientalistas se configuraram e em vista das quais adotaram determinadas estratégias de mobilização - , quanto para as dimensões simbólicas enfatizadas pela Teoria dos Novos Movimentos Sociais - como os contextos de micromobilização nos quais identidades coletivas foram construídas e frames, istoé, as interpretações da questão ambiental, foram gerados pelos ativistas. A partir dessa embocadura, argumentamos que ao longo de três estruturas de oportunidades políticas - o processo de Redemocratização, a Assembléia Constituinte e a Rio-92 - grupos de ativistas ambientalistas se formaram autonomamente e enfrentaram dilemas comuns relativos a seus frames e estratégias de mobilização. Ao longo delas, a articulação estratégica e simbólica entre tais grupos produziu uma rede de ativismo autonomeada "movimento ambientalista brasileiro"

\section{A FORMAÇÃO DOS GRUPOS AMBIENTALISTAS (1970-85)}

\section{A ESTRUTURA DE OPORTUNIDAdES POLÍTICAS DA REDE-} MOCRATIZAÇÃo A Teoria do Processo Político salienta que movimentos sociais surgem tipicamente quando mudanças nas oportunidades políticas, istoé, nas dimensões formais e informais do ambiente político, aumentam as possibilidades para grupos sociais se mobilizarem, abrindo ou criando novos canais para expressão de reivindicações ${ }^{10}$. Isso pode ocorrer de três maneiras ${ }^{11}$. Primeiro, pelo aumento de permeabilidade das instituições políticas e administrativas às reivindicações da sociedade civil, provocadas por crises na coalizão política no poder. Segundo, por mudanças no estilo de interações políticas entre o Estado e os movimentos sociais, especialmente a redução da repressão a mobilizações. Terceiro, pela presença de aliados potenciais, como movimentos sociais, partidos políticos, mídia e elites dissidentes. Tais fatores aumentam as possibilidades de os grupos sociais insatisfeitos expressarem suas demandas na arena pública.

No caso brasileiro, uma mudança na estrutura de oportunidades políticas (EOP) aconteceu com o início do processo de Redemocratização. As possibilidades de mobilização coletiva se expandiram na segunda metade dos anos 1970, quando eclodiu uma crise interna à coalizão que dirigia o regime. Vias de mobilização política foram abertas. As formas de expressão política foram liberalizadas em 1978 e a censura prévia aos meios de comunicação foi reduzida. No ano seguinte, a Anistia e a extinção do bipartidarismo propiciaram a diversificação de lideranças e a partidarização de movimentos sociais antes 
albergados ou simpáticos ao Movimento Democrático Brasileiro $(\mathrm{MDB})^{12}$.A Abertura culminou na seqüência de vitórias do MDB nas eleições para o Legislativo, executivos locais e governos de estado, em 1974, 1978 e 1982. Esse êxito constituiu um efeito demonstração para mobilizações de vários setores da sociedade civil — operários, profissionais liberais de classe média, funcionários públicos, moradores da periferia dos centros urbanos - , constituindo um ciclo de protesto ${ }^{13}$.

Quatro dimensões dessa nova estrutura de oportunidades políticas são decisivas para entender a emergência de protestos ambientais no Brasil. Primeiro, a Abertura significou um amainamento da repressão aos protestos sociais em geral. Segundo, os ativistas ambientalistas podiam contar com aliados em outros movimentos sociais, bem como na Igreja Católica e na Ordem dos Advogados do Brasil (OAB), apoiadores potenciais dos protestos contra o regime autoritário em fins dos anos 1970. Terceiro, as instituições políticas e administrativas se tornaram mais permeáveis às demandas da sociedade civil. Desde 1973, com a criação da Secretaria Especial do Meio Ambiente, o aparato burocrático-legal ambiental foi sendo incrementado com a criação de órgãos e legislação específica, fornecendo aos ativistas novos espaços políticos e novas estruturas de mobilização para veicular suas reivindicações. Por fim, durante a Redemocratização, estava em constituição uma agenda ambientalista internacional. A Conferência de Estocolmo, reunião da ONU sobre meio ambiente e desenvolvimento em 1972, abriu a discussão pública nacional sobre a questão ambiental no Brasil. Além disso, associações ambientalistas internacionais e partidos verdes nacionais recém-formados ofereciam novos modelos organizacionais e estratégias de mobilização.

Em conjunto, as dimensões da estrutura de oportunidades políticas da Redemocratização geraram as condições para a constituição dos grupos ambientalistas que darão a espinha dorsal do movimento brasileiro nos anos 1980 .

CONTEXTOS DE MICROMOBILIZAÇÃO E A FORMAÇÃO DE IDENTIDADES COLETIVAS Embora se possam descrever todos os grupos ambientalistas brasileiros surgidos no Brasil dos anos $1970 \mathrm{e}$ 1980 como membros das "classes médias", como fez Antuniassi, a extração social comum não é suficiente para caracterizá-los. Boa parte das mobilizações políticas do período contava com ativistas oriundos das classes médias. A variação entre os grupos se deve mais aos distintos "contextos de micromobilização" nos quais se formaram. Istoé, a microcontextos de interação social, tais como instituições profissionais, grupos culturais e redes de amizade, nos quais cidadãos comuns se convertem em ativistas ambientalistas. A conexão entre ativistas é, antes de mais nada, uma interação sociocultural e pessoal, por meio da qual inter-
[12] Kinzo, Maria D. G. Oposição e autoritarismo. Gênese e trajetória do $M D B, 1966-79$. São Paulo:Idesp/Vértice, 1988; Sallum Jr., Brasílio. Labirintos: dos generais à Nova República. São Paulo: Hucitec, 1996.

[13] Boschi, op.cit. 
[14] Gamson, Willian. "The social psychology of collective action". In: Mueller, Carol McClurg e Morris, Aldon D. (eds.). Frontiers in Social Movement Theory. New Haven / Londres:Yale University Press, 1992.

[15] Jasper,James.The art of moral protest. Culture, biography, and creativity in socialmovements. Chicago:The University of Chicago Press, 1997, p. 86.

[16] Por exemplo, nos Conselho Florestal Federal, Serviço Florestal do Ministério da Agricultura, Parque Nacional de Conservação de Itatiaia, Museu Nacional, Departamento de Pesquisas Florestais e Conservação da Natureza do IBDF (Urban, 2001).

[17] Bones, Elmar \& Hasse, Geraldo. Pioneiros da ecologia. Breve história do movimento ambientalista no Rio Grande do Sul. Porto Alegre: Já Editores, 2002 . pretações comuns, laços afetivos, lealdades comunitárias e o sentimento de pertencimento a grupos se constroem ${ }^{14}$. Nesse processo, emergem identidades coletivas, isto é, "percepções de distinção, fronteiras e interesses de grupo, alguma coisa próxima a uma comunidade" 15 .

Diferentes gêneros de experiência social e política conferem, portanto, feições particulares a cada grupo e definem distintos estilos de ativismo. No nosso caso, identidades ambientalistas emergiram a partir de quatro contextos de micromobilização.

Nas origens do ativismo ambientalista no Brasil está um grupo de perfil estritamente conservacionista: a Fundação Brasileira para Conservação da Natureza (FBCN), fundada em 1958 no Rio de Janeiro. Seus membros eram, sobretudo, engenheiros agrônomos e cientistas naturais, trabalhando na burocracia estatal e envolvidos com a questão ambiental por razões profissionais. A situação de funcionários públicos dos membros da FBCN deu-lhe desde sempre a feição de um grupo de interesse, procurando influir diretamente sobre as decisões de Estado, por meio de lobby, em detrimento de mobilizações públicas.Antes e durante o regime autoritário, essa estratégia foi bem-sucedida: a FBCN influenciou a criação de leis, órgãos e políticas ambientais e seus membros ascenderam aos cargos de direção na área ${ }^{16}$. Nesse sentido, a trajetória de seus membros se confunde com a montagem da própria burocracia ambiental brasileira, dando à $\mathrm{FBCN}$ um caráter paraestatal até a década de 1970.

Ao longo dos anos 1970 foram surgindo grupos que começaram a dar conotações mais políticas à questão ambiental.

AAssociação Gaúcha de Proteção ao Ambiente Natural (Agapan), fundada em 1971, em Porto Alegre,é, na origem, muito similar à FBCN. Também formada por pesquisadores de ciências naturais com interesse profissional no tema e muitos deles com contato prévio com associações conservacionistas locais. Como a FBCN, a Agapan se engajou na constituição da burocracia ambiental, influenciando a formulação de legislação e a implementação de políticas públicas ambientais, mas em nível estadual ${ }^{17}$. Todavia, a Agapan se diferenciava da FBCN no uso de estratégias de mobilização, especialmente campanhas de difusão de informação, palestras e formas simbólicas de manifestação. Por meio delas, a Agapan atraiu jovens ativistas da seara estudantil e foi progressivamente se aproximando do movimento pela Redemocratização.

O Movimento Arte e Pensamento Ecológico (Mape) surgiu em São Paulo, em 1973, formado por artistas plásticos, escritores e jornalistas vinculados aos movimentos contra-culturais e preocupados com a poluição urbana. O Mape se apropriou de estratégias expressivas e simbólicas dos novos movimentos sociais europeus e recorreu especialmente à linguagem artística como forma de expressão, organi- 
zando vernissages, happenings literários e atos lúdicos. O perfil de seus membros, sem expertise técnica na área, fez com que o Mape se mantivesse distante dos cargos públicos ambientais e se voltasse mais intensamente para a sociedade civil, inclusive para a mobilização em prol da Redemocratização.

Também em São Paulo se formou a Associação Paulista de Proteção Natural (APPN), em 1976, tendo por membros profissionais liberais e pequenos empresários, com experiência associativa ou política anterior.AAPPN nasceu como um protesto comunitário, reativo, contra uma obra governamental que impactava a área de residência de vários de seus ativistas: a construção de um aeroporto internacional na região sudoeste da Grande São Paulo. Por meio de estratégias de mobilização convencionais, como abaixo-assinados, a APPN mobilizou moradores da área potencialmente afetada e, como a Universidade de São Paulo (USP) estava ali situada, professores universitários de esquerda, que estabeleceram uma conexão com o $\mathrm{MDB}^{18}$. Assim, o protesto local ganhou uma nacionalização não-intencional, sendo encampado pelo movimento pela Redemocratização. Nesse sentido, a APPN sedimentou o vínculo, até então tênue, entre o ativismo ambientalista e os protestos políticos contra o governo autoritário.

Em cada um desses contextos de micromobilização, indivíduos isolados se constituíram como pequenos grupos de ativistas ambientais e emergiram diferentes gêneros de identidades coletivas como "ambientalistas" 19 : os técnicos, baseados em vínculos profissionais entre cientistas naturais, já incorporados à burocracia de Estado por profissão, e os políticos, de formação humanística e conectados com o movimento pela Redemocratização.

FRAMES AMBiENTAListAs Vários analistas dos movimentos sociais ressaltam que toda ação coletiva depende das habilidades dos ativistas de construir interpretações acerca da conjuntura em que estão imersos e, por meio delas, transformar descontentamento em mobilização. "Frames" são esses instrumentos cognitivos e guias para a ação que permitem aos ativistas questionar uma dada situação social antes não problemática, atribuir responsabilidade a grupos ou autoridades por tal estado de coisas e apresentar estratégias para alterá-loº.

Há dois frames típicos do ativismo ambientalista, segundo Diani. O "conservacionista" define o meio ambiente exclusivamente como mundo natural selvagem, vendo qualquer intervenção nele como questão técnica, restrita aos cientistas naturais. Já o frame "ecologia política” inclui o mundo urbano na definição do problema ambiental. As causas da degradação ambiental são atribuídas ao desenvolvimento capitalista e ao estilo de vida moderno. Daí se deriva uma crítica
[18] Antuniassi, op. cit., p. 26.

\begin{abstract}
[19] A distinção entre "técnicos" e "políticos" é de Sainteny, Guillaume. "Logiques d'engagement et logiques de rétribution au sein de l'ecologisme français". Cahiers Internationaux de Sociologie, vol. CVI, jan.-jun. 1999.
\end{abstract}

\footnotetext{
[20] Benford, Robert \& Snow, David. "Framing processes and social movements: an overview and assessment". Annual Review of Sociology, n. 26 , 2000, pp. 611-39.
} 
[21] “[...] a gente estava mais preocupado em salvar animais, criar áreas protegidas; $[. .$.$] algumas reservas$ deveriam ficar sem o uso [...] pelo homem [...] para proteger a biodiversidade" (membro da FBCN, entrevista, 12/8/2004).

[22] Lutzenberger apud Bones \& Hasse, op. cit., p. 187.

[23] “[...] padrões culturais-comportamentais uniformizadores [...] criam-se assim economias cada vez mais centralizadoras, de capital intensivo, com utilização de tecnologia bruta, pouca absorção de mão-deobra e desordenada exploração dos recursos naturais, satisfazendo a máxima do: USE E JOGUE FORA" (Boletim Peco, Mape, n. 1, 1978).

[24] "O que nós vemos atualmente é um crescimento econômico louco, erroneamente chamado desenvolvimento, que viola a natureza em todos os sentidos [e] mesmo ao homem. [...] E isto para uma fração da humanidade que se beneficia com este crescimento material, que tem roupas, casa e comida." ("Nós alcançamos o fim?", Manifesto da APPN, 1975). sociocultural à sociedade capitalista, jogando a discussão sobre meio ambiente para dentro da arena política.

O movimento ambientalista brasileiro obedece a essa disjuntiva.As variações de experiência e de percepções da EOP sobre a Redemocratização levaram os grupos de ativistas ambientalistas a desenvolver dois frames distintos: um conservacionista, outro socioambientalista.

A FBCN havia difundido no Brasil o conservacionismo clássico. No conteúdo, adotou uma visão biocêntrica da relação sociedadenatureza. O meio ambiente seria a natureza selvagem, a ser preservada da ação deletéria dos grupos sociais por meio de parques nacionais e reservas ambientais. $\mathrm{Na}$ forma, o discurso é cientificista: os especialistas das ciências naturais seriam autoridades incontestáveis na definição de problemas e de políticas ambientais. Dos dois ângulos, o conservacionismo segrega a questão ambiental de qualquer dimensão social e a apresenta como apolítica ${ }^{21}$. Embora a EOP da Redemocratização e mudanças de conjuntura internacional tenham constrangido a FBCN a incorporar em seu discurso o "manejo" de recursos naturais em áreas florestais já habitadas por populações tradicionais, o cerne de seu conservacionismo pouco se alterou, mantendo seu epicentro na preservação da fauna e da flora.

O socioambientalismo apenas emergiu com o processo de Redemocratização, adotado por praticamente todas as associações formadas nos anos 1970. Nesse frame, a definição do problema ambiental passa das ciências naturais para as humanas, com ênfase na relação entre processos sociais e naturais. O humanismo da contracultura é incorporado, sob a forma de demanda por uma "ética ecológica" ${ }^{22}$. A própria idéia de meio ambiente é redefinida como relação entre grupos sociais e recursos naturais. Essas dimensões sociais foram incorporadas de diferentes maneiras pelos ativistas brasileiros. A Agapan enfatizava questões rurais, como os agrotóxicos, enquanto o Mape criticava a degradação causada pela expansão da sociedade de consumo $^{23}$ e a APPN a associava ao "modelo brasileiro de desenvolvimento" ${ }^{24}$. Nesses dois últimos sentidos, o discurso ambiental incorporou a crítica ao processo de industrialização em curso no país nos anos 1970 e demandou alterações no estilo de vida urbano-industrial. Assim, o novo frame associou fortemente os problemas ambientais com causas políticas e econômicas. Por isso, o chamamos aqui de sociambientalismo.

Os dois frames, o conservacionista e o socioambientalista, passaram desde então a conviver em concorrência. $O$ fato de um ou outro ganhar ascendência em cada uma das fases de formação do movimento ambientalista brasileiro dependeu dos itens sob debate na agenda pública e da habilidade dos ativistas de vinculá-los às diferentes estruturas de oportunidades políticas. 
Ao reunir ativistas e construir identidades peculiares, os grupos ambientalistas formados ao longo dos anos 1970 fizeram parte do trabalho de construção de um movimento ambientalista no Brasil. Entretanto, o processo só pôde se completar quando os grupos se coordenaram entre si e uma ação efetivamente coletiva surgiu. Isso porque um movimento social não é um mero conjunto de ativistas, mas "redes de interação informal entre uma pluralidade de indivíduos, grupos e/ou organizações, engajados em conflitos políticos ou culturais, com base em identidades coletivas compartilhadas" 25 . Os grupos seguem suas próprias rotinas de mobilização, interagindo intensivamente entre si em momentos nos quais questões cruciais adentram a agenda pública. Em EOPs peculiares, desafios apresentados por oponentes ou oportunidades excepcionais para introduzir itens na agenda pública fortalecem os laços entre grupos e uma mobilização conjunta acontece. Nas EOPs em que vários grupos se organizam para expressar publicamente seus descontentamentos, um ciclo de protestos se configura ${ }^{26}$.

Para efetivamente se constituir como um movimento social, os grupos ambientalistas brasileiros, até então independentes, tiveram de resolver três sucessivos problemas de coordenação de sua ação coletiva: criar uma rede conectando-se entre si; definir estratégias de mobilização e desenvolver um frame comum. Cada um desses problemas foi resolvido em meio a três distintas estruturas de oportunidades políticas: o processo de Redemocratização, a Constituinte e Rio-92. Em cada uma delas, ciclos de protesto surgiram e os grupos ambientalistas tiveram de definir um conjunto mínimo de padrões de formas de pensar e agir comuns.

Ciclo de protestos Pela Redemocratização As primeiras coalizões entre grupos ambientalistas brasileiros se constituíram em fins dos anos 1970. Uma incipiente rede ambientalista surgiu sob a forma de campanhas conjuntas em torno de temas com possibilidade de engate no debate público mais amplo. O frame socioambientalista, ao atribuir as causas dos problemas ambientais ao "modelo brasileiro de desenvolvimento" implementado pelo regime autoritário, conectou imediatamente as mobilizações ambientalistas com a campanha pela Redemocratização.

Esse foi o caso da Campanha em Defesa da Amazônia, no final de 1978 , em oposição aos planos do governo federal de realizar contratos de exploração da Floresta Amazônica com empresas internacionais. Liderada pela APPN, e vinculando também à Agapan e ao Mape, a campanha ganhou o apoio do MDB e se transformou em Movimento em Defesa da Amazônia, abrangendo dezoito estados e o Dis-
[25] Diani, op.cit., p.13.

\footnotetext{
[26] Tarrow os define como "seqüências escalonadas de ação de maior freqüência e intensidade do que o normal, que se estende através de vários setores e regiões da sociedade. [E] Envolvem novas técnicas de protestos e novas formas de organização [...]" (Tarrow, Sidney. "Struggling to reform: social movements and policy change during cycle of protests". West. Soc. Pap, n. 15, Ithaca, Cornell University, 1983, p.36).
} 
[27] Evento típico dessa campanha foi um ato público em São Paulo em 15 de janeiro de 1979, que atraiu cerca de 1,5 mil pessoas e gerou uma "Carta Aberta à Nação Brasileira”, contra a internacionalização da Amazônia, e em defesa da preservação do estilo de vida das comunidades tradicionais que lá viviam.

[28] A mobilização mais significativa foi a passeata "Enterro das Usinas Atômicas”, em memória das vítimas de Hiroshima e em intenção das potenciais vítimas brasileiras, reunindo aproximadamente 1,2 mil pessoas (Urban, Teresa. Missão quase impossivel. Aventuras e desventuras do movimento ambientalista no Brasil. São Paulo: Petrópolis, 2001).

[29] Em 1985, o país contava com cerca de 400 grupos ambientais em funcionamento (Viola, Eduardo. "O movimento ambientalista no Brasil 1971-1991: da denúncia à conscientização pública para a institucionalização e o desenvolvimento sustentável". In: Goldenberg, Mirian (ed.). Ecologia, ciência e política. Rio de Janeiro: Revan, 1992, p. 57). trito Federal ${ }^{27}$. A outra grande coalizão no mesmo estilo foi a Campanha contra a Utilização de Energia Nuclear, pouco mais tarde, em 1980 , nas quais se engajaram as mesmas associações da campanha anterior, adensadas agora de associações ambientalistas menores recém-surgidas - como a Oikos (1982) e o Grupo Seiva de Ecologia (1980). O assunto atraiu um espectro maior de aliados dentre os membros do movimento pela Redemocratização: movimento estudantil, movimentos sociais populares, movimentos culturais, cientistas, políticos, artistas e religioso ${ }^{28}$. A terceira campanha de articulação do movimento foi o Adeus Sete Quedas, em 1982, contra a hidrelétrica de Itaipu. Liderada pelo Mape, a mobilização incluiu a Agapan, a APPN e outras associações menores, como a Seiva de Ecologia, e o Coletivo Verde (1985), formado por ex-exilados políticos influenciados pela contracultura.

Em todas essas campanhas, a existência de aliados na arena social e na política favoreceu as primeiras conexões relativamente estáveis entre grupos antes autônomos, configurando uma rede de ativismo ambiental. Essas mobilizações tanto motivaram a formação de novas associações ambientalistas ${ }^{29}$ quanto suscitaram um debate em torno do melhor formato organizacional para a coalizão emergente.

O Mape propôs uma federação ambientalista nacional, articulando as várias pequenas associações ambientalistas. Assim surgiu a Assembléia Permanente de Defesa do Meio Ambiente de São Paulo (Apedema), em 1983, visando manter o ativismo no plano da sociedade civil.Já a APPN investiu em aprofundar a articulação da rede de associações ambientalistas com o MDB. Todavia, os conflitos internos em torno da partidarização da questão ambiental acabaram por cindir a associação em pequenos grupos. A Agapan, por sua vez, procurou projetar seu principal ativista, José Lutzenberg, à condição de liderança nacional. Essa estratégia acabou sendo a mais bem-sucedida. Isso porque a Agapan, no frame e nas estratégias de ação, era transversal ao movimento, abarcando em seu discurso todo o espectro temático do movimento, desde o conservacionismo da FBCN, até temas urbanos e contraculturais, e todas as estratégias de mobilização, desde os lobbies e acesso à burocracia do Estado dos conservacionistas até manifestações públicas e lúdicas, preferidas pelos demais grupos. Por essas razões, a Agapan adquiriu centralidade na rede do ativismo ambientalista da década de 1970 e Lutzenberg tornou-se o broker entre a tradição conservacionista e os novos grupos socioambientalistas.

Assim, em meados dos anos 1980, estava configurada a primeira coalizão estável entre grupos de ativistas. As campanhas conjuntas indicam o estabelecimento de um campo ambiental, com liderança e agenda própria. Além disso, havia agora um frame dominante. O con- 
servacionismo da FBCN ficou na sombra. A agenda da Redemocratização ajudou a consolidar a abordagem politizada da questão ambiental: o socioambientalismo.

CiClo DE PROTESTOS DA CONSTITUINTE O período final da Redemocratização configura a segunda EOP relevante para a formação do movimento ambientalista brasileiro. Se na EOP anterior apenas coalizões tópicas em torno de temas específicos nos permitem falar de um movimento ambientalista, a perspectiva de uma Constituinte impôs a formação de coalizões mais estáveis, como forma de incluir temas ambientais na nova Constituição.

Por não serem instituições, movimentos sociais precisam inventar ou se apropriar de organizações e canais de elocução para levar a cabo sua expressão coletiva. Essas "estratégias de mobilização" incluem desde bases mais estáveis para o ativismo, como as associações, partidos, sindicatos e instituições públicas, atéestratégias informais, como eventos de protesto, redes e campanhas ${ }^{30}$. A nova estrutura de oportunidades políticas colocou como problema de ação coletiva, para a recém-constituída rede ambientalista, a definição da estratégia de mobilização mais adequada para inserir a temática ambiental na agenda política. Isso porque o processo de Redemocratização culminara em eleições gerais para uma Assembléia Constituinte, abrindo para o movimento a escolha entre manter as mobilizações no plano da sociedade civil ou organizar um partido próprio e ingressar na arena institucional, como vinham fazendo vários movimentos sociais.

No momento de convocação de uma Constituinte, coalizões entre os grupos ambientalistas se formaram em torno de diferentes estratégias. Primeiro, a desmobilização que acompanhou o fim da transição democrática levou parte dos ativistas ambientalistas a converter seus grupos de protesto em associações profissionalizadas, com atuação especializada. A SOS Mata Atlântica se constituiu em 1986 sob essa égide, combinando ativistas de agrupamentos anteriores, como a APPN e a FBCN, com grupos empresariais até então alheios à questão ambiental. Esse perfil mais especializado fez com que a SOS, assim como a FBCN, a Agapan e outras associações conservacionistas recém-constituídas, preferissem restringir sua relação com as instituições políticas ao lobby ou apoio a candidaturas de qualquer partido que encampasse propostas verdes. Já os grupos voltados para mudanças no estilo de vida, como o Mape e a Seiva de Ecologia, preferiam manter manifestações no âmbito da sociedade civil e lançar candidaturas avulsas de ativistas ou de simpatizantes do movimento ambientalista, sem vinculação com nenhum partido. A terceira possibilidade era lançar ou apoiar candidaturas dentro dos partidos de esquerda já organizados. A Oikos, uma dissidência da APPN, investiu nessa alter- 
[31] Os temas socioambientalistas eram a reação à degradação ambiental do estilo vida urbano ("humanização e despoluição das cidades - saneamento básico e reaproveitamento do lixo") e rural (problemas de saúde causados por agrotóxicos); os contraculturais giravam em torno do pacifismo ("fim da indústria armamentista") e da democratização das relações sociais ("fim de todas as formas de discriminação racial, sexual, religiosa ou ideológica"). O conservacionismo se restringia à "preservação da fauna nacional" e à "defesa dos ecossistemas brasileiros". Havia ainda um bloco replicando a agenda do movimento pela Redemocratização: descentralização política e econômica; poder local; democratização da imprensa etc. nativa. A quarta via, nunca antes aventada, era formar partido próprio como canal de representação política do movimento ambientalista. $O$ Coletivo Verde, no Rio, uma facção do Mape egrupos menores do ABC paulista e de Santa Catarina, eram favoráveis a um partido verde.

Nem todas essas alternativas se mostraram viáveis, porém. No final de 1985, definiu-se que as candidaturas à Constituinte só poderiam ser partidárias.Assim, a perspectiva de participar diretamente do processo constituinte, sem aval de um partido, desaparecia. Os ambientalistas então se dividiram diante das alternativas remanescentes. A coalizão liderada pelo Coletivo Verde encaminhou a criação do Partido Verde,em janeiro de 1986, reunindo ativistas isolados de pequenas associações, especialmente do Rio de Janeiro.A partir daí o PVliderou uma pequena coalizão, que lançou candidaturas próprias. Em contrapartida, outra coalizão se formou em torno da estratégia de apoiar candidaturas de diferentes partidos, desde que comprometidos com uma agenda ambiental mínima, composta pela agregação de temas socioambientalistas e conservacionistas, com pitadas de contracultura, numa "Lista Verde" 31 . Assim, no início de 1986, formou-se a primeira tentativa de formalização de uma rede ambientalista nacional, a Coordenação Interestadual Ecológica para a Assembléia Constituinte (CIEC).

Foi esta a estratégia mais bem-sucedida. Fábio Feldman, principal ativista da Oikos e defensor da Lista Verde, foi o único candidato apoiado pelo movimento a se eleger. Mesmo numa arena eminentemente institucional, como o Parlamento, as associações sobrepujaram o partido como forma mais eficaz de vocalização do movimento. Nesse sentido, o processo eleitoral em torno da Constituinte consolidou a estrutura associativa como forma mais eficiente de mobilização ambientalista que a partidária.

Além disso, a Assembléia Nacional Constituinte abriu canais de influência para movimentos sociais e grupos de interesse. A Constituinte funcionou, ao longo de 1987 e 1988 , sem um projeto preliminar e com uma estrutura descentralizada de subcomissões. Isso permitiu aos grupos sociais organizados pressionarem para a criação de subcomissões sobre assuntos de suas pautas. A sociedade civil podia também participar por meio de "Iniciativas Populares": 30 mil assinaturas possibilitavam enviar uma emenda à Assembléia Constituinte diretamente, sem a mediação de um deputado. Essas duas vias de participação no processo político foram mobilizadas pelos ativistas ambientalistas. De um lado, as articulações de Fábio Feldmann no parlamento resultaram na formação da subcomissão de Saúde, Segurança Social e Meio Ambiente, sob jurisdição do Comitê de Ordem Social. De outro lado, estratégias informais de mobilização, como abaixo-assinados, se mostraram tão ou mais eficientes do que uma estrutura partidária própria, o Partido Verde, como caminho para introdução de temas am- 
bientalistas no debate: os grupos ambientalistas conseguiram incluir 3 das 83 Iniciativas Populares aceitas na Constituinte ${ }^{32}$.

Durante o funcionamento da subcomissão, Feldman se consolidou como um broker entre as duas arenas de mobilização ambiental: a da sociedade civil e a da negociação institucional no Congresso. Essa combinação de estratégias resultou na proposição de um capítulo exclusivo sobre a questão ambiental na Constituição.

Todavia, a influência de grupos organizados da sociedade civil na elaboração do texto constitucional foi freada pela reação de um bloco de deputados e senadores de partidos de centro e direita. O "Centrão" obstou a aprovação de projetos de legislação à esquerda. $\mathrm{Na}$ área ambiental, bloqueou a proibição total de uso da energia nuclear e a criminalização de condutas ambientalmente incorretas.

Tais obstáculos levaram os grupos ambientalistas a convergirem, sedimentando coalizões nacionais entre si e ampliando alianças para fora do movimento. Sob liderança de Feldman, surgiu a Frente Nacional de Ação Ecológica, bloco parlamentar de apoio às propostas ambientalistas, repetindo a estratégia pragmática da Lista Verde ${ }^{33}$. A estratégia da Frente foi estimular a pressão direta das associações ambientalistas sobre os parlamentares, promovendo visitas a projetos de preservação e manejo ambiental.Assim, conseguiu apoio para assegurar os pontos conservacionistas do capítulo sobre meio ambiente na Constituição de 1988.

O ciclo de mobilização da Constituinte teve desdobramentos importantes para o processo de formação do movimento ambientalista brasileiro.

Do ponto de vista das estratégias de mobilização, a Constituinte ratificou as associações em detrimento do partido como principal maneira de coordenar a ação coletiva ambientalista. O processo eleitoral e o bloqueio do Centrão evidenciaram os limites da opção partidária do PV e, mesmo, de uma aliança política exclusivamente à esquerda. Além disso, ao consolidar novos instrumentos legais, como a ação civil pública, a Constituição abriu às associações civis a oportunidade de encaminhar demandas diretamente às instituições públicas, sem ter de recorrer a partidos. Finalmente, tendo sido mais influentes como "ambientalistas" do que como políticos profissionais durante a Constituinte, os ativistas vislumbraram o poder simbólico da expertise técnico-científica que se tornou, daí por diante, sua maneira preferencial de legitimar reivindicações na arena política.

Quanto aos frames de ação coletiva, a Constituinte começou com uma agregação temática, com dominância socioambientalista, expressa na Lista Verde. Todavia, as negociações lideradas pela Frente Nacional de Ação Ecológica deram relevo aos temas conservacionistas, mais palatáveis para deputados não-ambientalistas, basicamente
[32] Duas tratavam de reservas indígenas, contando com apoio de movimentos sociais ligados à Igreja. A terceira proibia o uso, mesmo pacífico, de energia nuclear.

[33] A Frente foi criada em junho de 1987 , por 71 associações ambientalistas, inclusive a FBCN, 9 senadores $e$ 82 deputados de esquerda e centroesquerda, mas também com apoio de parlamentares liberais e conservadores (Jornal da Tarde, 9/6/1987). 
[34] Foram aprovadas medidas de proteção da Floresta Amazônica, da Mata Atlântica, da Serra do Mar, do Pantanal e da Zona Costeira, e da diversidade genética do país e a proibição parcial do uso de energia nuclear ( $O$ Estado de S. Paulo, 26/5/1988). a proteção a ecossistemas, que virou o cerne do capítulo sobre meio ambiente na Constituição34.

Em suma, a EOP da Constituinte foi decisiva na formação do movimento ambientalista na medida em que consolidou vínculos e compromissos entre grupos de ativistas. A existência de um inimigo comum e a necessidade de encontrar aliados forçaram os grupos a suplantar suas diferenças. Ao menos momentaneamente, as identidades de grupo se esmaeceram em favor de uma identidade comum. Foi o que lhes deu capacidade de influenciar na regulação legal de questões ambientais na Constituição e sedimentou a aliança nacional de grupos até então dispersos.

O CICLO DE PROTESTOS DA RIO-92 Adecisão da Organização das Nações Unidas (ONU) de sediar sua segunda Conferência Mundial sobre Meio Ambiente e Desenvolvimento no Brasil em 1992 alterou mais uma vez a estrutura de oportunidades políticas para a rede de ativistas e se tornou evento decisivo na efetivação de um movimento ambientalista brasileiro. A Rio-92 trouxe um novo problema de coordenação da ação coletiva: a construção de um frame capaz de aglutinar os grupos ambientalistas.

A EOP da Rio-92 era, em princípio, desfavorável aos grupos ambientalistas. A vitória de Collor nas eleições presidenciais de 1989 fechara as agências estatais aos grupos ambientalistas dos anos 1980, usualmente alinhados com a esquerda. Sem acesso à burocracia ambiental e na vigência da normalidade democrática, vários desses grupos desapareceram ou profissionalizaram suas associações. De uma maneira ou de outra, distanciaram-se da arena política. $\mathrm{O}$ governo Collor ainda tentou atraí-los, nomeando José Lutzenberger, o líder ambientalista dos anos 1970, para a presidência da Secretaria Especial do Meio Ambiente. Lutzenberger, porém, perdera o status da década anterior. Saíra da Agapan e pouco se engajara nas mobilizações em torno da Constituinte, rompendo assim suas conexões com os grupos antigos sem ter constituído relações com os novos. Sem apoio do movimento e sem experiência partidária, não conseguiu se sustentar na arena política: ficou à margem das decisões na preparação da Conferência e abandonou o cargo antes de seu início.

O alijamento dos ativistas em relação ao governo nacional e o formato "participativo" da Conferência incentivaram a rede ambientalista a outra vez investir nas associações como forma de coordenação da ação coletiva e a buscar aliados no âmbito da sociedade civil, e não no Estado.

Durante os preparativos para a Rio-92, as coalizões formadas na Constituinte tentaram nova articulação nacional do movimento. A Frente Nacional de Ação Ecológica, liderada pela SOS Mata Atlântica, 
rearticulou grupos conservacionistas, enquanto o PV formou o movimento Pró-Rio 92, de feições socioambientalistas, incluindo membros do PT, grupos comunitários locais, movimentos sociais populares e, mesmo, setores do empresariado35.

Da mesma maneira que, na Constituinte, nenhuma das coalizões pôde se impor por si mesma, dado o escopo limitado de seus frames, a Frente se circunscrevia à seara conservacionista, enquanto o Pró-Rio não ultrapassava os limites do socioambientalismo. Tais tônicas exclusivas não coadunavam com a agenda da $\mathrm{ONU}$ para a Rio-92, sistematizada no Relatório Brundtland, que incluía ambas as temáticas.

A agenda da Conferência, mais do que a simples agregação de temas socioambientalistas e conservacionistas, propugnava uma nova maneira de definir a questão ambiental. A noção de desenvolvimento sustentável, propondo novas tecnologias para manejo racional dos recursos naturais, vinha apresentada como forma de conciliar desenvolvimento e preservação ambiental. Já a idéia de biodiversidade enfocava a manutenção do patrimônio genético de todas as formas de vida, inclusive das populações humanas habitando áreas de preservação.

A nova estrutura de oportunidades políticas compeliu os grupos ambientalistas a buscarem aliados para fora da rede estritamente ambientalista como meio de complementar sua agenda.

A SOS Mata Atlântica adotou a estratégia mais consoante com a nova EOP ao formar uma nova coalizão nacional com 1,1 mil associações, metade delas sem ativismo prévio em questões ambientaii ${ }^{36}$. Assim surgiu o Fórum Brasileiro de ONGs e Movimentos Sociais para o Meio Ambientee Desenvolvimento, em 1990, ocentro aglutinadore principal estrutura de mobilização da rede ambientalista durante a Rio-92.

A composição do Fórum pôs em questão a tônica conservacionista da agenda do movimento resultante da Constituinte. Os movimentos sociais traziam agendas marrons, criticando a desigualdade social, a distribuição iníqua dos impactos ambientais e o modelo global de desenvolvimento econômico. Em alternativa, propunham um novo padrão de modernização: o "desenvolvimento sustentável". Assim, esses novos aliados contribuíam para um reavivamento do socioambientalismo, reconectando a questão ambiental com a problemática do desenvolvimento, no espírito do Relatório Brundtland.

Isso não significou, contudo, o retorno à dominância do frame socioambientalista no interior da rede nacional. A nova coalizão era liderada pela SOS Mata Atlântica, grupo a meio caminho entre o conservacionismo e o socioambientalismo, que, como broker, orquestrou a convergência entre os dois frames originalmente contrastantes.

De uma parte, o frame socioambientalista foi matizado, movendose em direção ao conservacionismo. De fato, a noção de desenvolvimento sustentável compatibilizou a defesa simultânea de proteção
[35] SOS, Oikos e Cedi. "UNCED 1992 e as ONGS brasileiras", apud Santos, Selene S. C. Herculano, Entre o heroísmo e a cidadania. Rio de Janeiro: Tese de doutorado, IUPERJ, 1994, anexo 1.

[36] Landin, Leilah. A invenção das ONGs: do serviço invisível à profissão sem nome. Rio de Janeiro: Museu Nacional/UFRJ, 1993, p. 66-67. 
[37] “[...] você não tem como expandir o sistema sem considerar as populações tradicionais; as terras indígenas têm o dobro da extensão das unidades de conservação no Brasil, [...] você não pode ignorar elas [sic] numa estratégia de conservação [...] a gente usa a questão ambiental, do desenvolvimento sustentável, com fins que são, na verdade, sociais" (membro do ISA, entrevista, 31/8/2004).

[38] “[...] começou-se muito na proteção de espécies, a proteção de espécies mudou para proteção de habitate agora a proteção de habitat inclui o manejo sustentável dos recursos naturais e o bem-estar da população que está lá. [...], não se pensa mais simplesmente em passar uma cerca e não ter pessoas, mas em como tratar as pessoas no meio ambiente [...]; então é uma gradação [...]" (membro do WWF-Brasil, entrevista, 31/8/ 2004).

[39] Rootes, Christopher (ed.). , n. 79 , novembro, 2007 (no ambiental e de desenvolvimento socioeconômico, visando a redistribuição de recursos. No entanto, embora a dimensão macroeconômica dos problemas ambientais tenha permanecido, a ênfase na questão urbana, típica do sociambientalismo dos anos 1970, se deslocou para as condições de vida de grupos sociais vivendo em interação com o ambiente natural no campo ou na floresta ${ }^{37}$.

De outra parte, o frame conservacionista foi redefinido com a substituição da noção de ecossistema pela de biodiversidade. Por meio dela, a proteção do habitat foi dilatada para incluir grupos sociais em interação com áreas florestais, desde que com estilos de vida de "baixo impacto ambiental". Os patrimônios genético e cultural de comunidades indígenas e de populações tradicionais, como grupos extrativistas, tornaram-se objetos de preservação ambiental. As florestas, tema típico do conservacionismo clássico, foram revalorizadas como lócus da biodiversidade. Essa inclusão de dimensões não-urbanas da pauta marrom diferenciou esse novo frame da tradição conservacionista ${ }^{3}$.

Esse duplo processo de matizamento e conciliação gerou, pela primeira vez, um frame comum a todo o movimento: o neoconservacionismo. A polissemia das noções de desenvolvimento sustentável e de biodiversidade permitiu que grupos com agendas em princípio divergentes pudessem dartônica própria às mesmas categorias.Abarcando as questões sociais, típicas da pauta marrom, e os temas verdes da agenda global, o neoconservacionismo se tornou uma língua franca para todos os grupos do movimento ambientalista, dos pioneiros dos anos 1970 aos conversos em 1992. Portanto, o novo frame consolidou coalizões, até então restritas a dimensões estratégicas, em torno de significados. $O$ novo frame se materializou na Agenda 21, documento resultante da Rio92. Aí, itens da agenda ambiental global, como proteção das florestas (cap.11)eda diversidade biológica (cap.15), foram combinados a tópicas socioambientais, como a capacitação de grupos social mentevulneráveis para a obtenção de meios de subsistência sustentáveis (cap.3).

Para estabelecer-se, o neoconservacionismo teve de fazer dois expurgos na agenda socioambiental dos anos 1970.A tônica política foi substituída por uma abordagem técnica da questão ambiental, formulada por especialistas das associações profissionais dos anos 1990. Eo estilo de vida urbano deixou de ser o foco do ativismo, como fica patente na concentração da atuação das grandes associações ambientalistas dos anos 1990, SOS e Instituto Socioambiental (ISA), em áreas florestais. Nesse sentido, o movimento ambientalista brasileiro caminhou rumo a uma profissionalização e conseqüente despolitização da questão ambiental - processo similar ao europeu39.

O outro impacto do ciclo de mobilização da Rio-92 sobre o movimento foi a solidificação de uma nova estratégia de mobilização. As lideranças individuais dos anos 1970 e 1980 foram substituídas por coali- 
zões relativamente duradouras entre associações. Essas redes de ativismo, policêntricas e horizontais, como a Rede Mata Atlântica (1992), Aguapé - Pantanal, Rede de Educação Ambiental (2002), Rede Cerrado deOngs (1992) eo Grupo de Trabalho Amazônico (1992), tornaram-se o meio preferencial de articulação do movimento e de expressão de demandas nos anos 1990 em três sentidos: como base logística de grandes campanhas temáticas; como meio de receber e gerir financiamentos governamentais e internacionais; e como canal de lobbye pressão na formulação e implementação de políticas públicas nacionais.

Com as redes, o ativismo ambientalista brasileiro pôde, simultaneamente, ampliar seu raio de ação e se especializar em temas e áreas geográficas. Assim, o movimento ganhou uma estrutura simultaneamente descentralizada e institucionalizada.

AEOP da Rio-92 constituiu, portanto, a terceira etapa do processo de formação do movimento ambientalista brasileiro. Nesse momento, resolveu-se o problema de coordenação de significados entre grupos distintos, com a configuração de um frame comum ao movimento um todo. Nesse sentido, sua resultante foi a consolidação de um movimento ambientalista nacional.

\section{CONCLUSÃo}

Procuramos aqui explicar a formação do movimento ambientalista brasileiro recorrendo a uma síntese conceitual entre a Teoria do Processo Político e a Teoria dos Novos Movimentos Sociais, ainda pouco explorada nos estudos sobre os movimentos sociais brasileiros e latino-americanos. Analisando articuladamente as dimensões político-institucionais e as simbólicas intervenientes na constituição de um movimento ambientalista no Brasil, argumentamos que ela se explica por duas dinâmicas: a interação dos grupos de ativistas com as estruturas de oportunidades políticas e a articulação deles entre si.

Do primeiro ângulo, três estruturas de oportunidades políticas foram decisivas.A EOP da Redemocratização incentivou a organização de grupos de protestos na sociedade civil, encaminhando a conversão de simpatizantes ambientalistas em ativistas. Mas, para que esses grupos autônomos se convertessem em um movimento, foi preciso que respondessem conjuntamente a questões relativas à coordenação da ação coletiva suscitadas por duas outras EOPs. A Constituinte compeliu os ativistas a escolherem entre diferentes estratégias de mobilização disponíveis e os levou a convergirem para uma coalizão de associações, emvez de um partido, como forma prioritária de apresentar suas reivindicações na esfera pública. Já a Rio-92 impingiu à coalizão de associações a negociação de um único frame, cujo significado pudesse ser compartilhado pelo movimento como um todo. Assim, o conceito de EOP 
nos permitiu identificar os elementos peculiares a cada uma das diferentes conjunturas que efetivamente influíram na construção do que Jasper chamou uma "identidade de movimento".

De outra parte, a reconstrução dos contextos de micromobilização evidenciou que os ativistas não se mobilizaram em torno da questão ambiental em função de sua extração social, como argumentam as Teorias dos Novos Movimentos Sociais. Diferentes gêneros de experiência social e política fomentaram identidades coletivas ambientalistas.A articulação estratégica e simbólica entre esses grupos autônomos de ativistas numa mesma rede de ativismo não foi automática, como resultante da adesão a mesmos valores, como defende Viola. Negociações em torno de significados e formas de ação foram cruciais para que a conexão se viabilizasse. O próprio significado da "questão ambiental" foi continuamente transformado pelos grupos de modo a facilitar alianças. Mudanças nos frames foram requisitadas pelas estratégias dos agentes diante de cenários políticos também cambiantes. Foi como adaptação a novas EOPs que os dois frames inicialmente independentes - socioambientalismo e conservacionismo - convergiram para o neoconservacionismo. Foi essa a interpretação da questão ambiental mais passível de ser compartilhada por todos os ativistas ambientalistas, viabilizando uma ampla aliança entre grupos. Essa conexão dependeu ainda do recurso a mesmas estratégias de mobilização. $\mathrm{O}$ uso desse conceito nos permitiu evidenciar conexões entre grupos ambientalistas tanto no plano das formas duradouras de organização, como associações, partidos e redes, quanto no nível mais frouxo das ligações eventuais em manifestações, candidaturas eleitorais e lobbies. E, mais importante, evidenciou como mudanças de estratégias estiveram concatenadas com mudanças nas EOPs, não sendo, portanto, resultado da simples volição dos agentes.

Analisando a formação dos grupos e a negociação de frames e estratégias de mobilização, procuramos mostrar como a resolução de sucessivos problemas de coordenação da ação coletiva resultou numa identidade coletiva compartilhada. Isso não significa o desaparecimento das diferenças e conflitos entre os grupos, mas aponta seu sucesso em superar divergências rotineiras em EOPs decisivas. Quando lograram se apresentar como uma coalizão robusta, os ativistas conseguiram incluir a temática ambiental na agenda pública. Nesses momentos, sedimentaram sua identidade como "movimento ambientalista brasileiro".

Recebido para publicação em 15 de junho de 2007 .

\section{NOVOS ESTUDOS}

CEBRAP

79 , novembro 2007

pp. $151-167$
ANGELAALONSO é professora do Departamento de Sociologia da Universidade de São Paulo (USP)e coordenadora da Área de Conflitos Ambientais do Cebrap; VALERIANO COSTA é professor do Departamento de Ciência Política da Universidade Estadual de Campinas (Unicamp) e pesquisador da Área de Conflitos Ambientais do Cebrap; e DÉBORA MACiEl é professora de Sociologia da Faculdade de Direito de São Bernando do Campo e pesquisadora da Área de Conflitos Ambientais do Cebrap. 